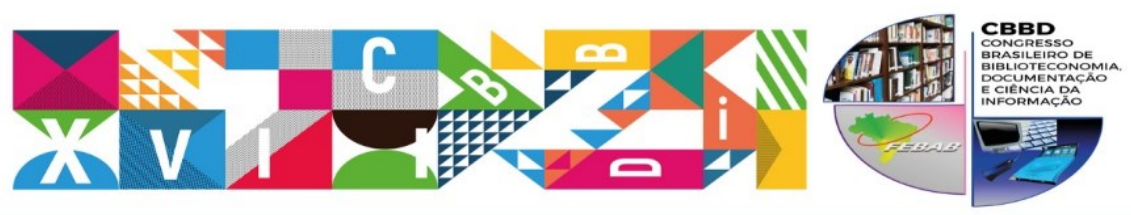

XXVII CONGRESSO BRASILEIRO DE BIBLIOTECONOMIA, DOCUMENTAÇĀO E CIÊNCIA DA INFORMAÇĀO

TEMA CENTRA: Objetivos para o Desenvolvimento Sustentável das Naçōes Unidas:
como as bibliotecas podem contribuir com a implementaçăo da Agenda 2030

Eixo 10 - 5 Seminário Nacional de Documentação e Informação Jurídicas

\title{
SUSTENTABILIDADE AMBIENTAL E DIREITO DE ACESSO À INFORMAÇÃO VERDADEIRA: de Estocolmo aos dias atuais
}

\author{
Lucivaldo Vasconcelos Barros \\ Professor associado do Instituto de \\ Ciências Sociais Aplicadas da \\ Universidade Federal do Pará. Pós- \\ doutorado em Ciência da Informação \\ pela Universidade do Porto. \\ E-mail: lucivaldobarros@gmail.com
}

\section{RESUMO}

Faz uma reflexão sobre a importância do direito de acesso à informação como instrumento de promoção da sustentabilidade ambiental. Tem como objetivo demonstrar o papel do Bibliotecário e das Bibliotecas na organização e disponibilização da informação ambiental como elemento fundamental para a construção de uma consciência cidadã em relação à proteção do meio ambiente e conhecimento da crise planetária vivenciada na contemporaneidade. Utiliza como método a pesquisa bibliográfica e uma breve pesquisa documental na legislação e documentos normativos nacionais e internacionais sobre os temas informação versus sustentabilidade ambiental, tais como Conferência de Estocolmo, Rio 92, Agenda 21, Lei de Acesso à Informação Ambiental, Lei da Política Nacional do Meio Ambiente, Lei de Acesso à Informação e Agenda 2030. Identifica com uma razoável clareza, em termos de resultados, a possibilidade das contribuições por parte dos profissionais da informação de atuar em diversas frentes no que tange à proteção ambiental, em particular no atingimento de objetivos e metas do Desenvolvimento Sustentável.

PALAVRAS-CHAVE: Sustentabilidade ambiental. Direito à informação. Informação ambiental. Objetivos do Desenvolvimento Sustentável. Agenda 2030.

\section{ABSTRACT}

Reflects on the importance of the right of access to information as an instrument to promote environmental sustainability. It aims to demonstrate the role of the Librarian and Libraries in the organization and availability of environmental information as a fundamental element for the construction of a citizen conscience regarding the protection of the environment and knowledge of the 


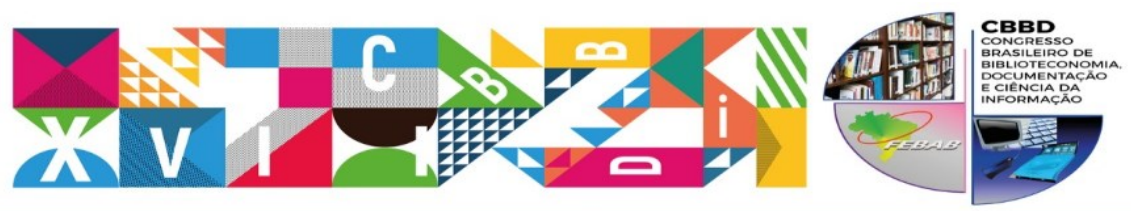

XXVII CONGRESSO BRASILEIRO DE BIBLIOTECONOMIA,

DOCUMENTAÇĀO E CIÊNCIA DA INFORMAÇĀO

TEMA CENTRAL: Objetivos para o Desenvolvimento Sustentável das Naçōes Unidas:
Como as bibliotecas podem contribuir com a implementaçăo da Agenda 2030

planetary crisis experienced in the contemporary world. It uses as a method bibliographical research and a brief documentary research in legislation and national and international normative documents on the topics information versus environmental sustainability, such as Stockholm Conference, Rio 92, Agenda 21, Law on Access to Environmental Information, Law on National Policy of the Environment, Access to Information Law and Agenda 2030. It identifies with a reasonable clarity, in terms of results, the possibility of the contributions of information professionals to act on several fronts with regard to environmental protection, in particular the attainment objectives and goals of Sustainable Development.

KEYWORDS: Environmental Sustainability. Right to information. Environmental Information. Objectives of Sustainable Development. Agenda 2030.

\section{DA CRISE PLANETÁRIA À SUSTENTABILIDADE AMBIENTAL}

O Relatório Meadows apresentado em 1968 pelo Clube de Roma deu início a um amplo debate sobre o esgotamento dos recursos ambientais do Planeta percebido naquele contexto. Em linhas gerais, o documento concluiu que o crescimento exponencial da economia moderna sucederia, num curto espaço de tempo, como consequência inevitável, uma catástrofe sem precedentes, colocando em risco a perpetuação da vida dos seres que habitam a Terra.

De acordo com Mota (2001), a Entidade “Clube de Roma”, na ocasião liderada por Aurelio Peccei e Alexander King, com apoio de cientistas de diferentes áreas, foi criada para propor um modelo de análise planetária futura, a partir da reunião de dados sobre população, alimentos, recursos naturais, produção e poluição.

A análise minuciosa do Relatório foi publicada em 1972 pelo cientista norteamericano Dennis Meadows em parceria com seus colaboradores, no livro "Os limites do crescimento". O consumo voraz de recursos e a emissão desenfreada de poluentes colocariam em xeque a sobrevivência da humanidade. Além de propor o congelamento do crescimento da população global e do capital industrial, Meadows (1997) mostrou a realidade dos recursos limitados e rediscutiu a velha tese malthusiana acerca do perigo 


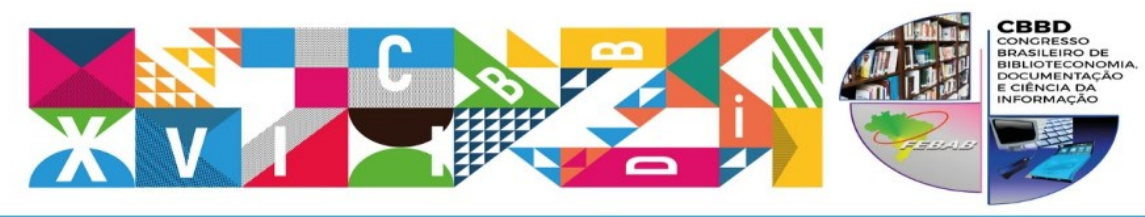

XXVII CONGRESSO BRASILEIRO DE BIBLIOTECONOMIA, DOCUMENTAÇÃO E CIÊNCIA DA INFORMAÇĀOO

TEMA CENTRA: Objetivos para o Desenvolvimento Sustentável das Naçôes Unidas:
como as bibliotecas podem contribuir com a implementaçāo da Agenda 2030

de crescimento descontrolado da população mundial.

No marco dessa reflexão, destacou-se também, nesse mesmo ano, na Suécia, a realização da primeira Conferência das Nações Unidas sobre o Meio Ambiente no âmbito internacional, mais conhecida como Conferência de Estocolmo ou simplesmente "Estocolmo 72". A edição do evento impulsionou as nações a estruturar seus órgãos de controle do meio ambiente, incentivando os países a estabelecer suas legislações relacionadas ao controle da qualidade ambiental.

Tais discussões polarizaram o embate sobre desenvolvimento econômico versus preservação ambiental, como um problema eminentemente sério e de resultados trágicos para a humanidade. Na mesma linha de orientação, McCormick (1992) corrobora aduzindo que a revolução ambientalista, permeada entre os anos de 1962 e 1970, foi impulsionada particularmente por seis fatores: 1) os efeitos da sociedade afluente; 2) a era dos testes nucleares; 3) o livro "A primavera silenciosa" (Silent spring), relatando os efeitos nocivos da má utilização de pesticidas e inseticidas químicos à base de Diclorodifeniltricloretano (DDT); 4) uma série de desastres ambientais bastante divulgados; 5) avanços nos conhecimentos científicos e 6) a influência de outros movimentos sociais.

Surge então uma nova conceituação para denominar as discussões em curso, identificada pelo termo "desenvolvimento sustentável", que passa a permear e integrar o debate sobre a crise ambiental planetária. Entretanto, cabe ressaltar que ao longo das reflexões o conceito passou por várias feições, evoluindo com o emprego de diversos vocábulos, como "crescimento econômico", "desenvolvimento econômico", "crescimento zero", "desenvolvimento sustentado", "ecodesenvolvimento", "desenvolvimento sustentável" e "sustentabilidade ambiental".

A palavra crescimento zero apareceu por volta de 1968, com a criação do Clube de Roma, como reação dos conservacionistas dos países ricos que defendiam uma taxa zero de crescimento econômico das nações em desenvolvimento. Como dito antes, o Relatório desse trabalho foi apresentado por Meadows, em 1972. Já a expressão ecodesenvolvimento foi utilizada pela primeira vez em 1973 por Maurice Strong, secretário-geral da Estocolmo72 e difundido conceitualmente por Ignacy Sachs, a partir 


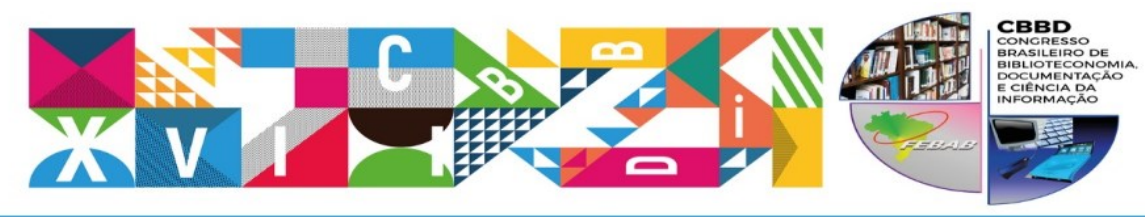

XXVII CONGRESSO BRASILEIRO DE BIBLIOTECONOMIA, DOCUMENTAÇÃO E CIÊNCIA DA INFORMAÇĀOO

IEMA CENIRAL: Objetivos para o Desenvolvimento Sustentável das Naçōes Unidas:
como as bibliotecas podem contribuir com a implementaçăo da Agenda 2030

de 1974. A ideia de desenvolvimento sustentável foi primeiramente divulgada por Robert Allen no artigo "Como salvar o mundo" (How to save the world), em 1980. Mais tarde, em 1987, o termo foi amplamente divulgado no Relatório Nosso futuro comum (Our common future) ou Relatório Brundtland, referência à primeira-ministra norueguesa Gro Harlem Brundtland, chefe da Comissão Mundial sobre Meio Ambiente e Desenvolvimento (CMMAD) na épooca (BRUNDTLAND, 1998; NOBRE; AMAZONAS, 2002; HERCULANO, 2006; MOTA, 2001; CAMARGO, 2003; MONTIBELLER FILHO, 1993).

Em linhas gerais, o desenvolvimento sustentável procura satisfazer as necessidades da geração atual, sem comprometer a capacidade das gerações futuras de satisfazerem as suas próprias necessidades. Em sua obra "Caminhos para o desenvolvimento sustentável", Sachs (2000) aponta algumas dimensões que integram o conceito "desenvolvimento sustentável": dimensão ecológica, dimensão social, dimensão econômica, dimensão ambiental, dimensão territorial, dimensão cultural, dimensão ética e política e institucional.

Com efeito, de forma sistematizada o conceito dos estudiosos acerca das várias vertentes da Sustentabilidade, tem-se:

a) Dimensão Ecológica: preservação do potencial do capital "natureza" na sua produção de recursos renováveis; limitar o uso dos recursos não renováveis (SACHS, 2000);

b) Dimensão Social: alcance de um patamar razoável de homogeneidade social; distribuição de renda justa; emprego pleno e ou autônomo com qualidade de vida decente; igualdade no acesso aos recursos e serviços sociais (SACHS, 2000). A disciplina procura abrir espaços de discussão para que os discentes possam conhecer melhor a sua realidade e interagir com outras diversidades;

c) Dimensão Econômica: avaliada a partir da sustentabilidade social propiciada pela organização da vida material (BRASIL, 2000);

d) Dimensão Ambiental: respeitar a capacidade de autodepuração dos ecossistemas naturais (SACHS, 2000);

e) Dimensão Espacial: norteada pelo alcance de uma equanimidade nas relações inter-regionais e na distribuição populacional entre o rural/urbano e o urbano (BRASIL, 


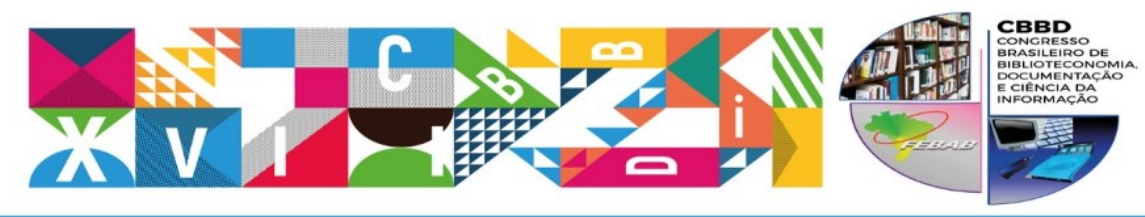

XXVII CONGRESSO BRASILEIRO DE BIBLIOTECONOMIA, DOCUMENTAÇÃO E CIÊNCIA DA INFORMAÇĀOO

TEMA CENTraL: Objetivos para o Desenvolvimento Sustentável das Naçóes Unidas:
como as bibliotecas podem contribuir com a implementaçāo da Agenda 2030

2000);

f) Dimensão Cultural: preservar os recursos naturais e envolver as comunidades na gestão de seu ambiente. Entrelaça-se aqui o direito humano a conservar a própria cultura e tradição. 0 respeito à diversidade étnica além de seu valor humano intrínseco, tem implicações para estratégias de apropriação e manejo dos recursos naturais (LEFF, 2001);

g) Dimensão Ética: a ética humana compreende a esperança na completude da humanidade, como consciência e cidadania planetária, aspiração e vontade, mas também aposta no incerto. Ela é a consciência individual além da individualidade (MORIN, 2000). A filosofia da disciplina busca valorizar espaços alternativos como locus de experimentação para uma prática ética, ecológica, solidária e sustentável. Na lição de Maturana (2000, p. 102) podemos compreender melhor esse significado quando enfatiza que a ética "aparece quando vemos o outro e também vemos as possíveis consequências do outro no nosso próprio comportamento; quando agimos dentro dessa compreensão de que o outro é um ser humano, que é um outro legítimo, e nos comportamos de acordo". Esse compromisso ético deve orientar a relação antrópica homem versus natureza, fundado no princípio da solidariedade que indica a plena realização do direito ao meio ambiente, não apenas à geração atual, mas a todas as gerações que vierem depois desta;

h) Dimensão Política e Institucional: a dimensão política mundial nesse cenário supranacional tornou-se muito complexa. Emergem as questões de natureza planetária, como a fome, o racismo e a degradação ambiental, que demandam soluções e esforços internacionais (JARA, 2001). A disciplina provoca o interesse das possibilidades, a partir da valorização local, com vistas a pensar nas relações institucionais; papel dos governos e suas políticas e diretrizes determinantes da configuração do meio ambiente.

Atualmente, enfim, há um consenso de que o conceito de sustentabilidade ambiental vem sendo incorporado cada vez mais pela sociedade, sendo a vertente ambiental dependente e inter-relacionada com as outras dimensões.

\section{DIREITO À INFORMAÇÃO E O PAPEL DAS BIBLIOTECAS NA AGENDA} 2030 


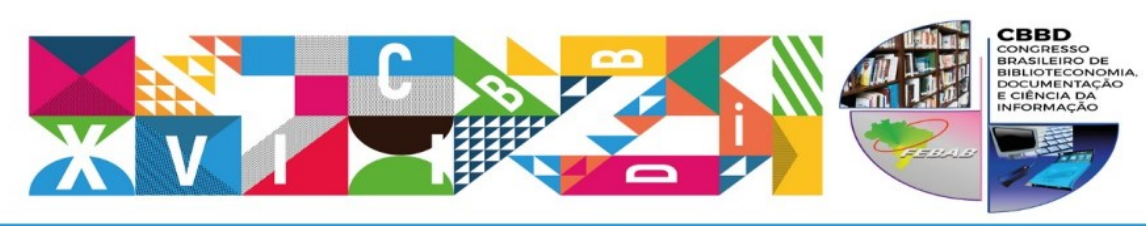

XXVII CONGRESSO BRASILEIRO DE BIBLIOTECONOMIA, DOCUMENTAÇÃO E CIÊNCIA DA INFORMAÇĀOO

TEMA CENTRAL: Objetivos para o Desenvolvimento Sustentável das Naçōes Unidas:
como as bibliotecas podem contribuir com a implementação da Agenda 2030

$\mathrm{Na}$ sociedade pós-industrial reconheceu-se a crescente importância da informação como elemento de visibilidade das ações do Estado no trato dos problemas ambientais que afligem a sociedade contemporânea.

A informação ambiental constitui uma ferramenta indispensável à construção de novos valores e atitudes, voltados ao desenvolvimento de uma sociedade comprometida com a solução de seus problemas ambientais, proporcionando condições adequadas de sobrevivência para as atuais e futuras gerações. Ademais, o direito de acesso à informação contribui para formar a consciência cidadã para a sustentabilidade ambiental.

É possível identificar o Princípio da Informação em vários diplomas jurídicos nacionais e internacionais. A Conferência de Estocolmo de 1972 traz a informação como princípio indispensável ao trabalho de educação em questões ambientais, visando assentar as bases de uma opinião pública bem informada e de uma conduta responsável dos indivíduos, das empresas e das comunidades. lema:

O Princípio 17 da Declaração de Estocolmo de 1972 traz como diretriz o seguinte

Confiar às instituições nacionais competentes a tarefa de planejar, administrar ou controlar a utilização dos recursos ambientais do Estado, com o fim de melhorar a qualidade do meio ambiente.

Em nível nacional o princípio 17 de Estocolmo impulsionou a criação de vários mecanismos legais brasileiros no que tange à proteção do meio ambiente e acesso à informação, podendo-se citar alguns exemplos dessa diretriz.

Um desses instrumentos foi a Lei n. 6.938, de 31 de agosto de 1981, que trata da Política Nacional do Meio Ambiente (PNMA). A respeito dessa Lei, pode-se afirmar que foi no âmbito legislativo que a informação e a educação ambiental passaram a ser inseridas nos diversos níveis de ensino, atingindo assim todas as comunidades para a defesa do meio ambiente. 0 ponto crucial da norma diz respeito ao Estudo de Impacto Ambiental (EIA), cujo objetivo é identificar impactos ambientais presentes nos empreendimentos econômicos. O resultado desse estudo deve ser traduzido em Relatório de Impacto Ambiental (Rima), por meio de uma linguagem acessível para a população conhecer a vantagem e desvantagem de um determinado empreendimento.

Assim, a Política Nacional de Meio Ambiente tornou a participação da sociedade 


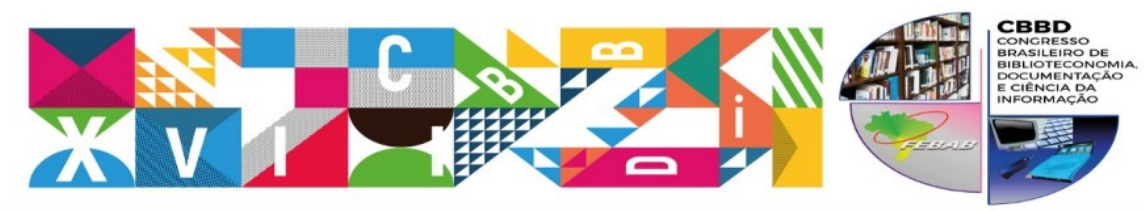

XXVII CONGRESSO BRASILEIRO DE BIBLIOTECONOMIA, DOCUMENTAÇÃO E CIÊNCIA DA INFORMAÇĀO

IEMA CENIRAL: Objetivos para o Desenvolvimento Sustentável das Naçōes Unidas:
como as bibliotecas podem contribuir com a implementaçăo da Agenda 2030

mais ampla no processo de licenciamento ambiental, instrumento obrigatório para prevenção de impactos ambientais quando representam riscos ao meio ambiente, sejam em suas fases de preliminar implantação ou operação com objetivo de minimizar e mitigar os riscos ambientais. Nesse contexto o acesso e o uso da informação ambiental passam a consistir um domínio urgente e necessário, por meio da institucionalização do Sistema Nacional de Informações sobre Meio Ambiente (Sinima).

Outro documento importante, decorrente da PNMA, foi a Resolução do Conselho Nacional do Meio Ambiente - Conama n. 1, de 23 de janeiro de 1986, ao versar no artigo 11 que o Relatório de Impacto Ambiental - Rima será “acessível ao público e suas cópias permanecerão à disposição dos interessados, nos Centro de Documentação ou Bibliotecas da SEMA e do órgão estadual de controle ambiental correspondente".

A Lei brasileira n. 9.795, de 27 de abril de 1999 instituiu a Política Nacional de Educação Ambiental (PNEA), dispôs sobre a difusão de informações para compreensão das questões ambientais. A informação surge então como um componente essencial para a consolidação da educação ambiental, sobretudo no Brasil onde o nível de acesso às informações sobre questões ecológicas ainda é baixo.

Por fim, a Constituição Federal de 5 de outubro de 1988, alçou o Direito de Acesso à Informação como garantia fundamental (art. 5ํㅜ, XIV e XXXIII) e destinou um capítulo inteiro para a causa da proteção do meio ambiente (Capítulo VI, art. 225).

Destaca-se ainda a Declaração do Rio, por ocasião da Conferência das Nações Unidas sobre Meio Ambiente e Desenvolvimento, realizada no Rio de Janeiro em 1992. Alguns princípios da Declaração de 92 estabelecem uma forte vinculação com acesso à informação ambiental:

Princípio 10: A melhor maneira de tratar as questões ambientais é assegurar a participação, no nível apropriado, de todos os cidadãos interessados. No nível nacional, cada indivíduo terá acesso adequado às informações relativas ao meio ambiente (...).

Princípio 19: Os Estados fornecerão, oportunamente, aos Estados potencialmente afetados, notificação prévia e informações relevantes acerca de atividades (...).

Outro documento resultante da Rio 92 foi a Agenda 21, instrumento de 


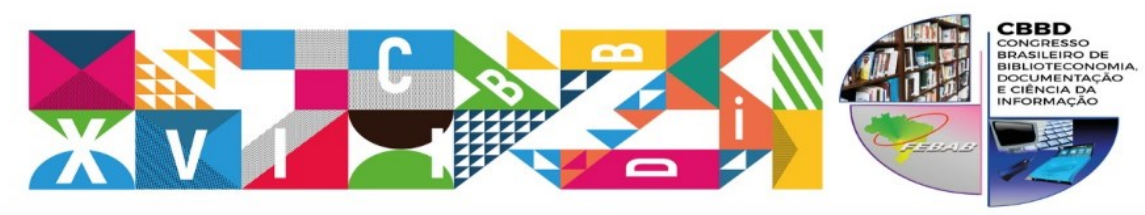

XXVII CONGRESSO BRASILEIRO DE BIBLIOTECONOMIA, DOCUMENTAÇÃO E CIÊNCIA DA INFORMAÇĀO

IEMA CENIRAL: Objetivos para o Desenvolvimento Sustentável das Naçōes Unidas:
como as bibliotecas podem contribuir com a implementaçăo da Agenda 2030

planejamento participativo visando o Desenvolvimento Sustentável, cuja filosofia também reforça o princípio da informação e a sustentabilidade ambiental.

A Lei n. 10.650, de 16 de abril de 2003 introduziu o acesso à informação ambiental no Brasil ao versar sobre acesso público aos dados e informações existentes nos órgãos e entidades integrantes do Sistema Nacional do Meio Ambiente - Sisnama. É possível extrair do art. $2^{\circ}$ um conceito para "informação ambiental":

documentos, expedientes e processos administrativos que tratem de matéria ambiental e todas as informações ambientais em meio escrito, visual, sonoro ou eletrônico, especialmente as relativas a: I - qualidade do meio ambiente; II - políticas, planos e programas potencialmente causadores de impacto ambiental; III - resultados de monitoramento e auditoria nos sistemas de controle de poluição e de atividades potencialmente poluidoras, bem como de planos e ações de recuperação de áreas degradadas; IV - acidentes, situações de risco ou de emergência ambientais; V - emissões de efluentes líquidos e gasosos, e produção de resíduos sólidos; VI - substâncias tóxicas e perigosas; VII - diversidade biológica; VIII - organismos geneticamente modificados.

Para chancelar e consolidar o direito de acesso à informação, previsto na Carta Magna de 1988, foi promulgada a Lei n. 12.527, de 18 de novembro de 2011, que regula o acesso a informações inserido no inciso XXXIII do art. 5ํㅜ, no inciso II do $\S 3^{\text {o }}$ do art. 37 e no $\S 2^{\circ}$ do art. 216 da Constituição Federal.

Do ponto de vista teórico, o Direito à Informação tem três dimensões: o direito de informar; o direito de se informar e o direito de ser informado. Desse modo, para a integralização da transparência administrativa, a obrigação de informar do Estado deve respeitar e levar em consideração a faculdade da livre expressão e manifestação da informação (direito de informar), bem assim a possibilidade de o próprio indivíduo buscar as suas informações (direito de se informar). A participação ativa do sujeito nessas duas dimensões é essencial à manutenção e concretização do tripé do direito à informação, atuando simultânea e complementarmente nos três níveis mencionados (MIRANDA, 1992; CANOTILHO; MOREIRA, 2007).

A primeira dimensão do direito à informação - o direito de informar - consiste basicamente num direito individual que assegura a faculdade e a liberdade de veicular, 


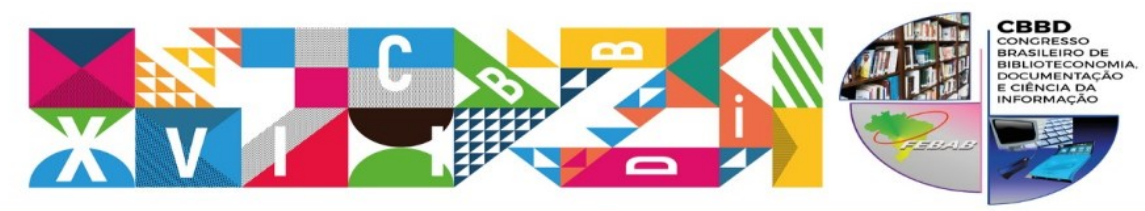

XXVII CONGRESSO BRASILEIRO DE BIBLIOTECONOMIA, DOCUMENTAÇÃO E CIÊNCIA DA INFORMAÇĀOO

IEMA CENIRAL: Objetivos para o Desenvolvimento Sustentável das Naçōes Unidas:
como as bibliotecas podem contribuir com a implementaçăo da Agenda 2030

transmitir ou comunicar informações a outrem (forma negativa), de difundi-las sem impedimentos, obstrução ou censura por parte do Estado (forma negativa) e também a meios de informar (forma positiva). 0 direito de informar na sua versão positiva ocorre, por exemplo, quando alguém tem o direito a um horário no rádio ou na televisão, ou o direito de resposta ou, ainda, o direito de antena, este último garantido pela legislação brasileira apenas aos partidos políticos em épocas eleitorais (direitos a meios para informar). Em suma, o direito de informar é o direito público subjetivo e individual de transmitir informações a terceiros, inclusive à coletividade, respeitada a dignidade, a honra e a imagem da pessoa humana (CANOTILHO; MOREIRA, 2007; NUNES JÚNIOR, 1997; CARVALHO, 2002).

A origem histórica do direito de informar está na liberdade de imprensa e alcança toda e qualquer pessoa ou entidade, pública ou privada, que tenha interesse em expressar ou manifestar o conhecimento sobre algo. A liberdade de expressão exige isenção política e ideológica dos governos, e a informação divulgada deve ser sempre de interesse público. Quando a divulgação implicar prejuízo à imagem, à privacidade ou à intimidade da pessoa humana e não ficar comprovado o interesse público é plenamente cabível pleitear ao Judiciário a reparação do dano sofrido, sem que isso seja interpretado como censura, conforme o entendimento apressado de algumas pessoas.

A liberdade da informação pública é necessária para uma compreensão esclarecida da coletividade, acerca de questões importantes, inclusive como fator de sobrevivência comunitária. 0 direito à informação, afirma Cartaxo de Arruda (1997, p. 248), "constitui a base para o direito à participação, visto que sem esta jamais poderá o indivíduo formar sua opinião e manifestar-se ou até mesmo intervir por meio do Poder Judiciário".

De outro lado, Canotilho e Moreira (2007, p. 572) afirmam que a liberdade de expressão "pode revestir a forma de silêncio ou de não falar ('não responder', 'não ter opinião', 'preferir não se pronunciar') e de não ser coagido a partilhar ou defender opiniões alheias ('liberdade de expressão negativa')".

A segunda dimensão - o direito de se informar - é o direito individual e coletivo, que consiste na faculdade de o indivíduo buscar informações desejadas sem qualquer 


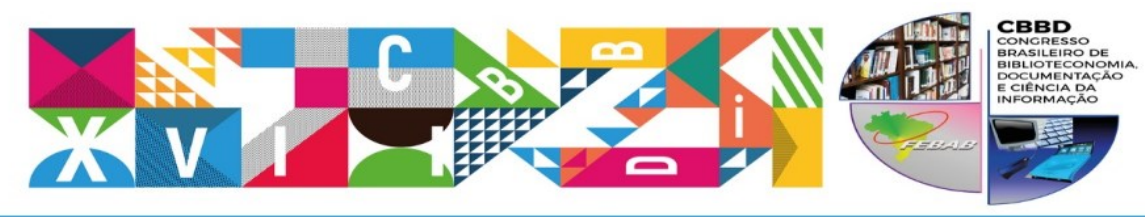

XXVII CONGRESSO BRASILEIRO DE BIBLIOTECONOMIA, DOCUMENTAÇÃO E CIÊNCIA DA INFORMAÇĀOO

IEMA CENIRAL: Objetivos para o Desenvolvimento Sustentável das Naçōes Unidas:
como as bibliotecas podem contribuir com a implementaçăo da Agenda 2030

espécie de impedimento ou obstrução. Seu objeto é a liberdade de busca de dados, fontes de informação ou documentos perante o poder público, para atender interesse da pessoa ou da coletividade, banindo qualquer espécie de impedimento. Os documentos de caráter público produzidos pelo Estado não devem sofrer restrições e os agentes públicos devem oferecer condições adequadas de acessibilidade. Embora existam algumas restrições legais à recolha de informações armazenadas em certos arquivos secretos, como os serviços de informação, por exemplo, o direito de se informar é o direito "de não ser impedido de se informar" (CANOTILHO; MOREIRA, 2007, p. 573). 0 cidadão tem direito de acesso aos arquivos públicos, admitindo-se o sigilo tão-somente em relação aos documentos cuja revelação possa provocar grave dano aos interesses da Nação ou da sociedade. Nessa mesma linha, fica também assegurado a qualquer indivíduo o direito de buscar, em bancos de dados particulares, informações de interesse particular.

Inclui-se, ainda, no direito de se informar, o direito de investigação dentro dos parâmetros constitucionais estabelecidos (CARVALHO, 2002). A regra prevalente, porém, é sempre o interesse público, tanto nos casos de livre acesso como nos casos de restrição ou violação da informação (sigilo, segredo, privacidade, intimidade etc.).

Essa face do seu caráter facultativo, essa dimensão do direito à informação requer uma enérgica participação do indivíduo, tendo em vista que a não-participação implica uma aceitação tácita do que está acontecendo. Nesse enfoque, Winkin (1998) e Loures (2004) afirmam que o ator social participa da comunicação não só com suas palavras, seus gestos, seus olhares, mas também com seus silêncios e apatias, pois a população ignorante permite que o direito seja utilizado como instrumento de dominação.

Finalmente, a terceira vertente - o direito de ser informado - corresponde ao dever do Estado de informar sobre suas ações. É a versão positiva do direito de se informar, consistindo na faculdade de ser mantido integral e corretamente informado, tendo por conteúdo o recebimento de informações fidedignas pelos poderes públicos e pelos meios de comunicação sobre quaisquer fatos de interesse público, bem como o pleno e adequado acesso a elementos mantidos em arquivos públicos, de interesse público ou particular. Essa versão do direito à informação vincula o Estado ao dever de proporcionar adequada educação, dando condições de apreensão ao receptor, conforme leitura do art. $5^{\circ}$, XXXIII, 


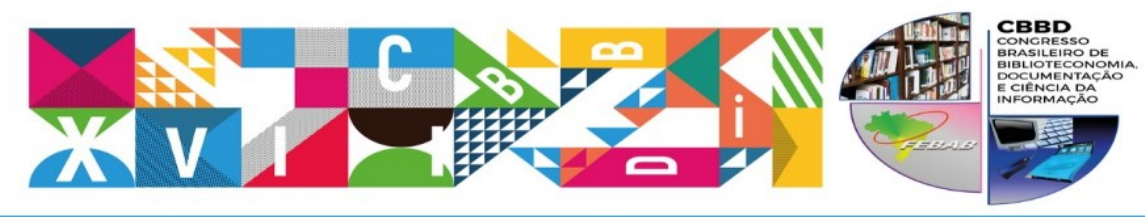

XXVII CONGRESSO BRASILEIRO DE BIBLIOTECONOMIA, DOCUMENTAÇĀO E CIÊNCIA DA INFORMAÇĀOO

IEMA CENIRAL: Objetivos para o Desenvolvimento Sustentável das Naçōes Unidas:
como as bibliotecas podem contribuir com a implementaçăo da Agenda 2030

da Constituição Federal, combinado com outros dispositivos da mesma espécie.

Daí se extraem dois componentes básicos: o primeiro, de que qualquer órgão ou empreendimento, seja público ou privado, deve informar contínua, veraz, completa e tempestivamente à administração pública acerca do meio ambiente; segundo, caso tais organismos não enviem as informações ou dados necessários, o próprio poder público deve agir na coleta dessas informações, ou, como diz a legislação pátria, "produzi-las quando inexistentes" (art. 9o , XI, da Lei n. 6.938, de 31/08/1981).

Tais premissas demonstram que o direito de ser informado, entendido como o direito a ser mantido constante e integralmente informado, não apresenta caráter absoluto no âmago da Constituição Federal de 1988, isso porque, como já foi explicitado anteriormente, esse direito apresenta uma face bilateral, pois só se pode afirmar que alguém esteja investido do direito de ser informado, quando o mesmo ordenamento atribua a outrem o dever de prestar tais informações.

Existe aí uma integração do processo informativo, dentro do qual há uma reciprocidade de posição, ou seja, "aquele que em dado momento informa, em outro está a receber informações, da qual, de resto, depende para o próprio desenvolvimento do seu pensamento" (BASTOS, 2001, p. 90). Em face disso, o direito de acesso às informações socioambientais pressupõe o dever do poder público de informar periodicamente a população sobre o estado do meio ambiente e sobre as ocorrências ambientais importantes.

Como se vê, o art. 5ํㅜ XXXIII da Constituição brasileira, explica sistematicamente Barros (2008), estabelece que todos os indivíduos têm o direito de "receber dos órgãos públicos informações de seu interesse particular, ou de interesse coletivo ou geral”, e o art. $37, \S 1^{\circ}$, determina que "a publicidade dos atos, programas, obras, serviços e campanhas dos órgãos públicos deverá ter caráter educativo, informativo ou de orientação social”, donde se extrai que o poder público tem o dever de prestar tais informações. Logo, no que concerne às atividades públicas, o indivíduo tem o direito de se inteirar dos fatos de forma constante. Nessa linha de orientação, pode-se dizer que a Carta Magna não atribui a nenhum organismo privado, de caráter informativo ou não, o dever de prestar informações. 


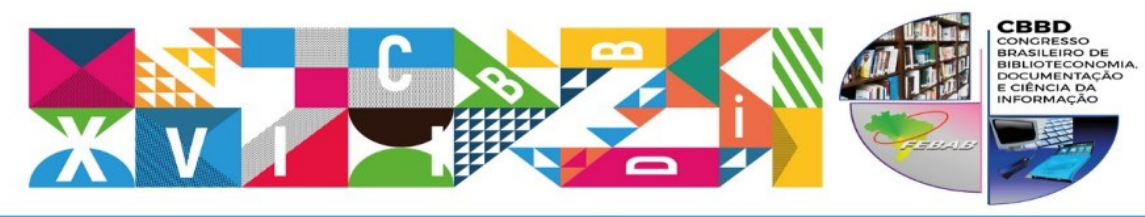

XXVII CONGRESSO BRASILEIRO DE BIBLIOTECONOMIA, DOCUMENTAÇÃO E CIÊNCIA DA INFORMAÇĀOO

TEMA CENTRA: Objetivos para o Desenvolvimento Sustentável das Naçôes Unidas:
como as bibliotecas podem contribuir com a implementaçāo da Agenda 2030

Do exposto resulta claro, portanto, que o direito a receber informações, em princípio, no regime constitucional brasileiro, fica restrito aos assuntos relativos às atividades do poder público. Tal entendimento, contudo, também não é absoluto. Em determinadas situações o particular também tem o dever de prestar informações, não diretamente a um indivíduo ou à coletividade, mas por força de mandamento constante em lei ou em decisão administrativa ou judicial. É o que ocorre, por exemplo, no licenciamento ambiental, em que, a própria iniciativa privada fica obrigada a prestar informações ao órgão público licenciador, devendo o ente estatal, por sua vez, prestar publicidade à sociedade em geral (art. 225, IV, da Constituição Federal de 1988).

Portanto, o particular deve prestar à administração pública as informações que a lei e os procedimentos administrativos e judiciais exigirem, e mais, está obrigado também, perante qualquer cidadão, a fornecer as informações que detenha sobre suas atividades desenvolvidas, desde que tais informações estejam sujeitas a potenciais riscos ambientais.

Por conclusão, a garantia de acesso à informação deve também se cercar de atributos morais e elementos éticos como: organização, utilidade, clareza, tempestividade, atualidade, objetividade, acessibilidade, qualidade, imparcialidade, completude e veracidade. Sobre o último atributo, diz-se que a informação verdadeira é condição indispensável para se conhecer a realidade da problemática ambiental da atualidade.

Para que a sociedade tenha garantido o acesso à informação de forma efetiva e verdadeira, o conjunto de informações sobre meio ambiente existente deve também atender a critérios técnicos da Ciência da Informação, como nível de acesso à informação, acessibilidade e seus critérios, formas práticas de pesquisa de informação e sobretudo dotar as bases de dados de padrões de encontrabilidade informacional.

Outro destaque consiste em afirmar que as alternativas para o desafio da problemática ambiental se revestem de caráter multi e interdisciplinar, sobre as quais recaem responsabilidades, atribuições e decisões amparadas por diversas disciplinas (CARIBÉ, 1992). Desse modo, Mueller (1992) enfatiza que a geração de informações sistemáticas sobre o meio ambiente requer um esforço multidisciplinar envolvendo elementos das Ciências Naturais, da Economia, da Demografia e da Sociologia, sendo a superposição de temas dessas áreas, a característica principal da transversalidade. 


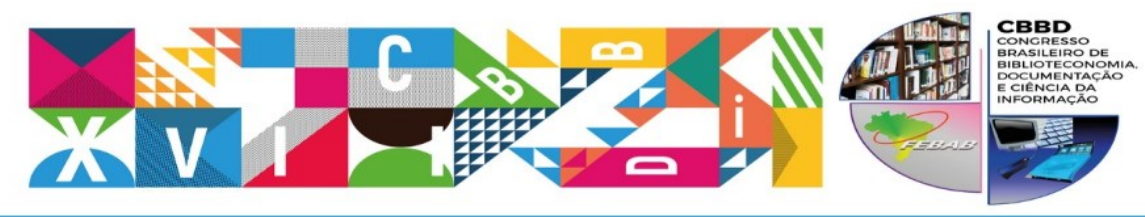

XXVII CONGRESSO BRASILEIRO DE BIBLIOTECONOMIA, DOCUMENTAÇÃO E CIÊNCIA DA INFORMAÇĀOO

TEMA CENTRA: Objetivos para o Desenvolvimento Sustentável das Naçōes Unidas:
como as bibliotecas podem contribuir com a implementaçăo da Agenda 2030

Entretanto, para o autor, a solução para o desenvolvimento de moldura conceitual para um sistema de informações ambientais levará tempo até que se chegue a um consenso sobre a questão.

No que concerne à Agenda de Desenvolvimento Sustentável Pós-2015, agora chamada de Agenda 2030, esta corresponde ao conjunto de programas, ações e diretrizes que orientarão os trabalhos das Nações Unidas e de seus países-membros rumo ao Desenvolvimento Sustentável. Concluídas em agosto de 2015, as negociações da Agenda 2030 culminaram em documento ambicioso que propõe 17 Objetivos do Desenvolvimento Sustentável (ODS) e 169 metas correspondentes.

Um dos Objetivos do Desenvolvimento Sustentável, o de referência 16.10 consiste em "assegurar o acesso público à informação". Os objetivos e metas são ambiciosos, mas necessários, pois no caso brasileiro, estudos (BRASIL, 2006) apontam que o nível pessoal de informação do brasileiro sobre meio ambiente é muito baixo, onde 14\% consideramse bem informados e apenas $3 \%$ consideram-se muito bem informados.

De outro lado, nem sempre o fato de possuir informação e conhecimento significa ter consciência. Como exemplo, o sujeito que, mesmo compreendendo com clareza as consequências decorrentes do mau uso da água, toma uma atitude deliberada provocando o seu desperdício (comportamento ativo), ou simplesmente nada faz para conter o uso inadequado desse recurso hídrico (comportamento passivo), desprezando, em ambos os casos, a informação e o conhecimento apreendidos anteriormente.

Do mesmo modo, observe-se, também, que mais informação disponível nem sempre é melhor. Em algum momento a quantidade de informação pode ter sido importante, em outro contexto tal aspecto apresenta-se como prejudicial. Hoje, com a multiplicação dos canais de comunicação do mundo pós-moderno vige uma espécie de ansiedade pela informação, daí o desafio de profissionais da informação (bibliotecários, jornalistas, web designers, publicitários, arquivistas e outros) de facilitar e filtrar as informações de qualidade, contribuindo para a ampliação da participação nos processos decisórios do governo, para a compreensão dos processos econômicos, sociais e políticos, assim como seus conflitos em sede nacional e internacional. A grande questão é saber selecionar o que é relevante para determinada escolha ou tomada de decisão. E isso, é 


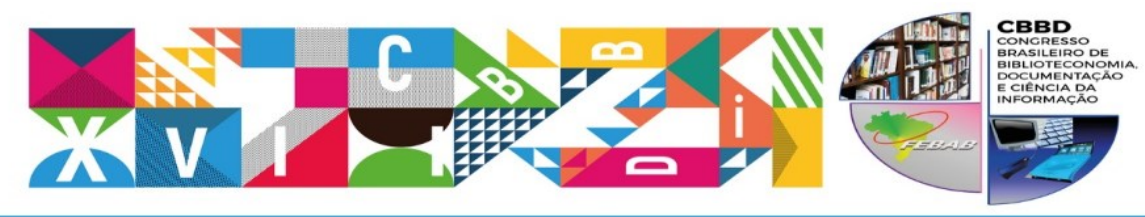

XXVII CONGRESSO BRASILEIRO DE BIBLIOTECONOMIA, DOCUMENTAÇÃO E CIÊNCIA DA INFORMAÇĀOO

TEMA CENIRAL: Objetivos para o Desenvolvimento Sustentável das Naçōes Unidas:
como as bibliotecas podem contribuir com a implementaçâo da Agenda 2030

lógico, exige não apenas a capacidade de saber reconhecer o que é importante, mas também a capacidade de ignorar o que não tem sentido. 0 que parece ser informação na verdade trata-se de manipulação (WURMAN, 1991; LAZARTE, 2000; DEMO, 2000; SILVEIRA, 2000).

Voltando ao exemplo do uso da água, o agir consciente não significa necessariamente se posicionar a favor do meio ambiente. Aquele que, mesmo sabendo das consequências danosas à natureza, desperdiça água também age com consciência. Não existe, portanto, neutralidade nem mesmo para aquele que adota uma postura passiva, porque, de qualquer modo, o seu posicionamento tende a favorecer um dos polos envolvidos na disputa.

Assim, conhecer não supõe, necessariamente, garantia de transformação. É comum encontrar pessoas altamente capacitadas acerca de questões sociais ou ambientais, mas suas práticas não se coadunam com as teorias sustentadas.

Se o acesso à informação visa promover o conhecimento e a consciência das pessoas, e se as pessoas com conhecimento encontram limites para transformar uma realidade, então qual seria a forma adequada de neutralizar essas dificuldades?

Com certeza não há uma resposta ou fórmula mágica para esse problema. É impossível fazer chegar a todos, de maneira idêntica, a mesma informação. Cada qual recebe uma informação e a utiliza de acordo com seu livre-arbítrio, livre no sentido de atribuir-lhe uma escolha e, portanto, uma destinação de uso.

O indivíduo eticamente ignorante (no mal sentido da palavra) pode até possuir a capacidade de discernir o que é certo ou errado dentro dos valores e costumes da sociedade em que vive, mas não consegue ser dono do seu próprio destino, porque o seu discernimento material prevalece sobre o seu sentimento espiritual.

De acordo com a escolha de que cada homem dispõe, ou ainda, de qual atitude tomar após receber uma informação, é possível atuar ou não na ordem (e na desordem) local e global. Logo, ao transformar um comportamento individual, o homem atua em uma dimensão espaço-temporal muito maior do que aquela da realidade imediata.

Não há como transformar o mundo exterior se o interior permanece imutável. De acordo com os ensinamentos socráticos, a sabedoria está naquele que conhece os limites 


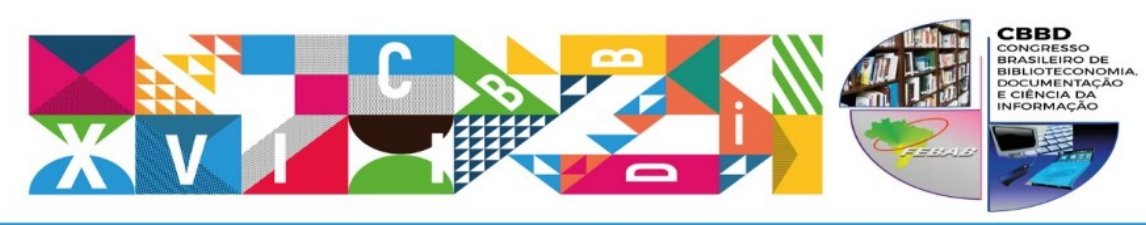

XXVII CONGRESSO BRASILEIRO DE BIBLIOTECONOMIA, DOCUMENTAÇÃO E CIÊNCIA DA INFORMAÇĀOO

TEMA GENrRaA: Objetivos para o Desenvolvimento Sustentável das Naçōes Unidas:
como as bibliotecas podem contribuir com a implementação da Agenda 2030

da própria ignorância e age para transformar seu próprio interior. Disso tudo, uma conclusão parece óbvia: o ignorante desinformado (no bom sentido do termo) sempre delega a sua escolha a um terceiro, na maioria das vezes de forma gratuita.

A escolha depende de um senso subjetivo, alojado no sentimento interno de cada indivíduo e que conduz o comportamento humano. Por isso se diz que a ignorância interior (ética, moral ou solidária) é às vezes mais nociva que a ignorância instrucional (é possível encontrar um analfabeto consciente, no sentido de não-ignorante). A informação, portanto, designa o conteúdo de tudo aquilo que se troca com o mundo exterior e que faz com que a ele se ajuste de forma perceptível. No sentido genérico da palavra, “a informação é aquilo que se acrescenta a uma representação" (MOLES, 1978, p. 36).

\section{CONCLUSÃo}

A informação é o fundamento para uma decisão livre e aquele que dispõe de mais recursos informacionais tem melhores condições de fazer uma avaliação melhor sobre determinado risco ambiental.

Mesmo hoje, embora o volume de informação tenha acumulado consideravelmente, torna-se cada vez mais difícil de ser processada, organizada e assimilada pela sociedade. Isso é um problema grave, pois informação desorganizada gera desinformação.

Para tal desafio, as Bibliotecas e os Bibliotecários precisam assumir o protagonismo da história atual em relação à proteção do meio ambiente, contribuindo estrategicamente para atingir os objetivos e as metas do Desenvolvimento Sustentável.

Particularmente em relação ao acesso à informação, pode-se concluir que a informação ambiental comporta três componentes: o primeiro consiste no elemento técnico, que é a própria informação, onde o Bibliotecário possui habilidades técnicas para organizar e colocá-la à disposição do usuário. O segundo componente representa o elemento de ordem ética, que é a responsabilidade do Bibliotecário e de qualquer cidadão, ao assumir o compromisso com a proteção ambiental. O terceiro (e o último componente) é traduzido em elemento prático, situado no âmbito do comportamento e traduzido na 


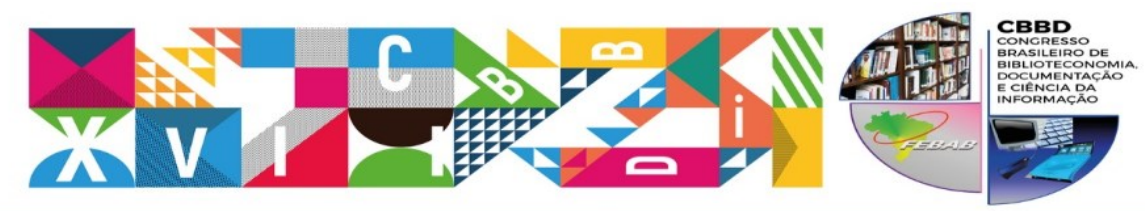

XXVII CONGRESSO BRASILEIRO DE BIBLIOTECONOMIA,

DOCUMENTAÇĀO E CIÊNCIA DA INFORMAÇĀO

TEMA CENTRAL: Objetivos para o Desenvolvimento Sustentável das Naçōes Unidas:
como as bibliotecas podem contribuir com a implementação da Agenda 2030

atitude de cada ser humana no cuidado com o meio ambiente.

\section{REFERÊNCIAS}

BARROS, Lucivaldo Vasconcelos. O Estado (In)Transparente: limites do direito à informação socioambiental no Brasil. Tese (Doutorado em Desenvolvimento Sustentável). Centro de Desenvolvimento Sustentável. Universidade de Brasília. 2008.

BASTOS, Celso Ribeiro. Comentários à Constituição do Brasil: promulgada em 5 de outubro de 1988 - arts. $5^{\circ}$ a 17. 2. ed. atual. São Paulo: Saraiva, 2001. 9 v. v. 2. 701 p.

BRASIL. Ministério do Meio Ambiente. Ciência e tecnologia para desenvolvimento

sustentável: subsídios à elaboração da Agenda 21 brasileira. Brasília: IBAMA, 2000.

o que os brasileiros pensam sobre a biodiversidade: pesquisa nacional de opinião: março de 2006: (comparação dos dados dos estudos de 1992 - 1997 - 2001). Rio de Janeiro: ISER; Brasília: MMA, 2006. 61 p.

BRUNDTLAND, Gro Harlen. Nosso futuro comum: [relatório da] Comissão Mundial sobre o Meio Ambiente e Desenvolvimento. 1. ed. Rio de Janeiro: FGV, 1988. 430 p.

CAMARGO, Ana Luiza de Brasil. Desenvolvimento sustentável: dimensões e desafios. Campinas: Papirus, 2003. $159 \mathrm{p}$.

CANOTILHO, José Joaquim Gomes; MOREIRA, Vital. Constituição da República Portuguesa anotada. 1. ed. São Paulo: Editora Revista dos Tribunais, 2007. 1152 p.

CARIBÉ, Rita de Cássia do Valle. Subsídios para um sistema de informação ambiental no Brasil. Ciência da Informação, Brasília, v. 21, n. 1, p. 40-45, jan./abr. 1992. Disponível em: <http://revista.ibict.br/ciinf/article/view/462>. Acesso em: 1 out. 2017.

CARTAXO DE ARRUDA, Geovana Maria. A participação pública na defesa do meio ambiente: implementação de um desenvolvimento sustentável. In: CONGRESSO INTERNACIONAL DE DIREITO AMBIENTAL, 2., 1997, São Paulo. Anais ... São Paulo: Instituto O Direito por um Planeta Verde, 1997. 628 p. p. 239-255.

CARVALHO, Márcia Haydée Porto de. A defesa da honra e o direito à informação. Florianópolis: Letras Contemporâneas, 2002.133 p.

DEMO, Pedro. Ambivalências da sociedade da informação. Ciência da Informação, Brasília, v. 29, n. 2, p. 37-42, maio/ago. 2000.

HERCULANO, Selene. Em busca da boa sociedade. Niterói: Ed. UFF, 2006. 426 p.

JARA, Carlos Julio. As dimensões intangíveis do desenvolvimento sustentável. Brasília: IICA, 2001. 

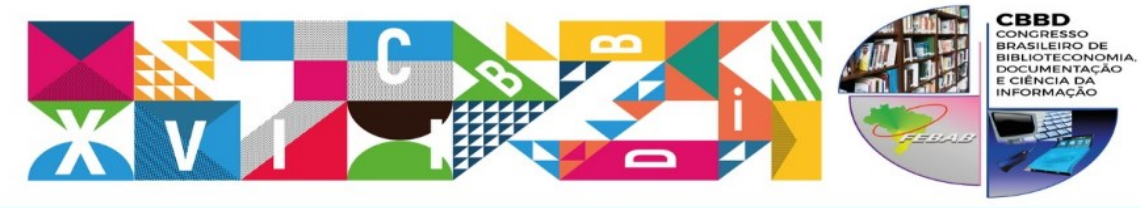

XXVII CONGRESSO BRASILEIRO DE BIBLIOTECONOMIA, DOCUMENTAÇĀO E CIÊNCIA DA INFORMAÇĀO

TEMA CENrRaA: Objetivos para o Desenvolvimento Sustentável das Naçōes Unidas:
como as bibliotecas podem contribuir com a implementação da Agenda 2030

LAZARTE, Leonardo. Ecologia cognitiva na sociedade da informação. Ciência da Informação, Brasília, v. 29, n. 2, p. 43-51, maio/ago. 2000.

LOURES, Flávia Tavares Rocha. A implementação do direito à informação ambiental. Revista de Direito Ambiental, São Paulo, v. 9, n. 34, p. 191-208, abr./jun. 2004.

MATURANA, Humberto. Transdisciplinaridade e cognição. In: Educação e transdisciplinaridade. Brasília: Unesco, 2000. p. 83-114.

MCCORMICK, John. Rumo ao paraíso: a história do movimento ambientalista. Tradução de Marco Antônio Esteves da Rocha e Renato Aguiar. Rio de Janeiro: Relume-Dumará, 1992. 224 p.

MEADOWS, Dennis. The limits to growth: a global challenge; a report for the Club of Rome Project on the Predicament of Mankind. In: NELISSEN, Nico; VAN DER STRASTEN, Jan; KLINKERS, Leon (Ed.). Classics in environmental studies: an overview of classic texts in environmental studies. Utrecht: International Books, 1997. pt. 3, Cap. 14. p. 195-198.

MIRANDA, Jorge. 0 direito de informação dos administrados. In: SARAIVA, Paulo Lopo (Coord.). Antologia luso-brasileira de direito constitucional. Brasília: Brasília Jurídica, 1992. p. 207212.

MOLES, Abrahan. Teoria da informação e percepção estética. Brasília: Ed. UnB, 1978. 308 p. MONTIBELLER FILHO, Gilberto. Ecodesenvolvimento e desenvolvimento sustentável: conceitos e princípios. Textos de Economia, Florianópolis, v. 4, n. 1, p. 131-142, 1993.

MORIN, Edgar. Os sete saberes necessários à educação do futuro. São Paulo: Cortez; Brasília: UNESCO, 2000.

MOTA, Carlos Renato. As principais teorias e práticas de desenvolvimento. In: BURSZTYN, Marcel (Org.). A difícil sustentabilidade: política energética e conflitos ambientais. Rio de Janeiro: Garamond, 2001. 259 p. p. 27-40.

MUELLER, Charles Curt. Situação atual da produção de informações sistemáticas sobre o meio ambiente. Ciência da Informação, Brasília, v. 21, n. 1, p. 14-22, jan./abr. 1992. Disponível em: <http://revista.ibict.br/ciinf/article/view/459/459>. Acesso em: 1 out. 2017.

NOBRE, Marcos; AMAZONAS, Maurício de Carvalho. Desenvolvimento sustentável: a institucionalização de um conceito. Brasília: Ibama, 2002. 368 p.

NUNES JÚNIOR, Vidal Serrano. A proteção constitucional da informação e o direito à crítica jornalística. São Paulo: FTD, 1997. 135 p. (Coleção juristas da atualidade).

SACHS, Ignacy. Caminhos para o desenvolvimento sustentável. Rio de Janeiro: Garamond, 2000. $95 \mathrm{p}$.

SILVEIRA, Henrique Flávio Rodrigues da. Um estudo do poder na sociedade da informação. Ciência da Informação, Brasília, v. 29, n. 3, p. 79-90, set./dez. 2000.

WINKIN, Yves. A nova comunicação: da teoria ao trabalho de campo. Campinas: Papirus, 1998. 

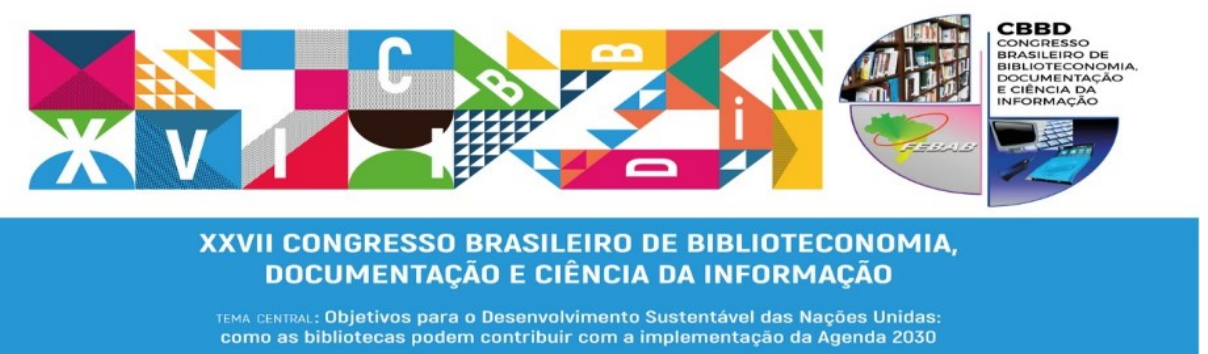

$216 \mathrm{p}$.

WURMAN, Richard Saul. Ansiedade de informação: como transformar informação em compreensão. 1. ed. Tradução de Virgílio Freire. São Paulo: Cultura Editores Associados, 1991. $380 \mathrm{p}$. 